УДК 338.431 .8

https://doi.org/10.32634/0869-8155-2021-354-11-12-158-162

Оригинальное исследование/Original research

Лещева М.Г. 1 ,

Юлдашбаев Ю.А. ${ }^{2}$

1 ФГБОУ ВО «Ставропольский государственный аграрный университет», 355017, г. Ставрополь, пер. Зоотехнический, 12

2 РГАУ-МСХА им. К.А.Тимирязева, 127500, г. Москва, Верхняя аллея, д. 4, корпус 15

Ключевые слова: сельские территории, государственная поддержка, комплекс мероприятий, методический подход

Для цитирования: Лещева М.Г., Юлдашбаев Ю.А. Методология разработки комплекса мероприятий по развитию сельских территорий. Аграрная наука. 2021; 354 (11-12): 158-162.

https://doi.org/10.32634/0869-8155-2021-354-11-12-158-162

Конфликт интересов отсутствует

Marina G. Leshcheva ${ }^{1}$, Yusupian A. Yuldashbayev ${ }^{2}$

${ }^{1}$ Stavropol State Agrarian University, Zootekhnicheskiy lane, 12, Stavropol, 355017, Russia

2 RGAU - Moscow Agricultural Academy named after K.A.Timiryazev, Verhnaya alley, 4, building 15 , Moscow, 127500

Key words: rural areas, state support, a set of measures, methodological approach

For citation: Leshcheva M.G., YuldashbaevY.A. Methodology for the formulation of a set of measures for the development of rural areas. Agrarian Science. 2021; 354 (11-12): 158-162. (In Russ.)

https://doi.org/10.32634/0869-8155-2021-354-11-12-158-162

There is no conflict of interests

Методология разработки комплекса мероприятий по развитию сельских территорий

\title{
РЕЗЮМЕ
}

Актуальность. Современное состояние сельских территорий характеризуется слабым развитием инженерной и социальной инфраструктуры, низким, по сравнению с городским, уровнем жизни, негативными формами миграции, естественной убылью и депопуляцией сельского населения. В рамках государственного регулирования процесса преодоления сложившегося положения предусмотрена господдержка мероприятий по развитию сельской местности, выдвинутых на основе местных инициатив (муниципалитетами, гражданами, профессиональными сообществами). Однако общепринятых научных рекомендаций по разработке таких мероприятий в настоящее время не выработано. Таким образом, тема исследования является актуальной.

Методы. Исследования проведены на основе системного, диалектического, абстрактно-логического, организационного подходов. Объектом исследования являются сельские территории, предметом - теоретические и методические вопросы, связанные с разработкой мероприятий по их развитию.

Результаты. Предложен методический подход к разработке комплекса мероприятий по развитию сельских территорий с учетом возможностей, предусмотренных действующими государственными программами. Он включает следующие этапы: анализ состояния сельской территории; прогнозирование направлений и динамики ее развития; определение объективных потребностей и выбор наиболее целесообразных изменений свойств сельской территории; разработку комплекса мероприятий и обоснование механизмов их реализации. В предложенном методическом подходе сельская территория рассматривается не изолированно, а в единой системе расселения «город - село» на основе использования SWOT- и PEST-анализа. На этапе прогнозирования направлений и динамики развития сельской территории предлагается комплексное использование нормативно-ресурсного метода и метода экстраполяции трендов временных рядов. Выбор наиболее целесообразных изменений свойств сельской территории осуществляется на основе многоуровневого подхода, позволяющего выделить проблемы сельского поселения, отдельных социальных групп и сельских жителей. Обоснование механизмов реализации мероприятий по развитию сельских территорий предложено осуществлять исходя из ресурсов муниципалитетов, сельского населения, частного бизнеса и мер государственной поддержки.

\section{Methodology for the formulation of a set of measures for the development of rural areas}

\section{ABSTRACT}

Relevance. The current state of rural areas is characterized by poor development of engineering and social infrastructure, low, compared to urban, standard of living, negative forms of migration, natural decline and depopulation of the rural population. Within the framework of state regulation of the process of overcoming the current situation, state support is provided for measures for the development of rural areas put forward on the basis of local initiatives (ofmunicipalities, citizens, professional communities). However, generally accepted scientific recommendations for the formulation of such measures are not currently developed, so the topic of the study is relevant.

Methods. The research is based on systematic, dialectical, abstract-logical, and organizational approaches. The object of the study is rural territories, the subject is theoretical and methodological issues related to the formulation of measures for their development.

Results. A methodological approach to the formulation of a set of measures for the development of rural areas, taking into account the opportunities provided by the current state programs, is proposed. It includes the following stages: analysis of the state of the rural territory; forecasting the directions and dynamics of its development; determination of objective needs and selection of the most appropriate changes in the properties of the rural territory; formulation of a set of measures and justification of mechanisms for their implementation. In the proposed methodological approach, the rural territory is considered not in isolation, but in a single system of settlement "city village" based on the use of SWOT and PEST analysis. At the stage of forecasting the directions and dynamics of rural development, a comprehensive use of the normative resource method and the method of extrapolation of time series trends is proposed. The selection of the most appropriate changes in the properties of the rural territory is carried out on the basis of a multi-level approach that allows to identify the problems of rural settlements, individual social groups and rural residents. It is proposed to justify the mechanisms for implementing measures for the development of rural areas based on the resources of municipalities, rural population, private business and state support measures.

Поступила: 14 сентября

После доработки: 22 сентября

Принята к публикации: 28 сентября
Received: 14 September

Revised: 22 September

Accepted: 28 September 


\section{Введение}

Современное сельское развитие характеризуется противоречивыми тенденциями. С одной стороны, наблюдается прирост производства сельскохозяйственной продукции, отрасль формирует существенный вклад в темпы роста ВВП страны, на основе импортозамещения обеспечивает ее продовольственную безопасность (таблица 1).

В то же время состояние сельских территорий нельзя признать удовлетворительным. Его признаками являются слабое развитие инженерной и социальной инфраструктуры, низкий, по сравнению с городским, уровень жизни, негативные формы миграции, естественная убыль и депопуляция сельского населения. Такое положение актуализирует необходимость государственного регулирования и послужило основанием для принятия государственной программы Российской Федерации «Комплексное развитие сельских территорий» [1]. В ее основе лежит концепция, в соответствии с которой государственную поддержку получают проекты развития сельской местности, выдвинутые на основе местных инициатив (муниципалитетами, гражданами, профессиональными сообществами). Таким образом реализуется подход «снизу вверх», который в большей степени, чем Государственная программа развития сельского хозяйства и регулирования рынков сельскохозяйственной продукции, сырья и продовольствия, учитывает местные потребности, предоставляя жителям сельских территорий возможность самостоятельно определять, что и в какой сфере их жизни наиболее востребовано. Успех разработки и реализации программных мероприятий в этих условиях зависят от четкого видения перспектив развития территории, понимания того, какие мероприятия способны дать максимальный внешний и внутренний эффект, задействуя существующие механизмы государственного регулирования.

Ведомственная целевая программа «Аналитическая и информационная поддержка комплексного развития сельских территорий», утвержденная Приказом Минсельхоза России от 20.04.2020 № 211, предусматривает в этих целях реализовать ряд мероприятий информационной, методической и популяризационной направленности. Однако общепринятых научных рекомендаций по разработке комплекса мероприятий, направленных на развитие сельских территорий, в настоящее время не выработано.
Имеющиеся методики касаются формирования стратегий социально-экономического развития субъектов Российской Федерации [2], правил отбора проектов в рамках ведомственной целевой программы «Современный облик сельских территорий» государственной программы Российской Федерации «Комплексное развитие сельских территорий» [3] и лишь частично могут использоваться для решения местных проблем долговременного и сбалансированного сельского развития.

Научно-методические публикации по данной тематике весьма ограничены. Фундаментальные основы развития регионов как целостных систем заложены В. Алонсо, Х. Армстронгом, Х. Ричардсоном, Дж. Тейлором. Принципы разработки стратегий развития сельских территорий сформулированы в работах М.Ю. Федотовой, А.А. Ломакина [4]. Систематизации научных основ их формирования посвящены исследования А.И. Костяева [5]. Некоторые методологические подходы к разработке региональных программ социального развития села раскрыты в трудах Бондаренко Л.В. [6]. Факторы, институты и механизмы опережающего развития сельских территорий изучены в работах Б.А. Ковтуна, В.Н. Папело, В.В. Ярманова [7]. Организация планирования их социального развития находит отражение в публикациях Шевченко В., Белоусова В., Белоусова А. [8].

Недостаточное методическое обеспечение и отсутствие необходимых компетенций у представителей местных органов власти, инициативных сельских жителей ограничивает эффективное использование потенциала государственной поддержки, заложенного в государственных программах и национальных проектах, что подтверждает опыт реализации федеральной целевой программы «Социальное развитие села» и ведомственной целевой программы «Устойчивое развитие сельских территорий».

Этим определяется цель исследования - разработать методические подходы к формированию комплекса мероприятий по развитию сельских территорий с учетом мер, предусмотренных действующими государственными программами.

\section{Материалы и методы}

Теоретической и методологической основой исследования послужили современная экономическая теория, труды отечественных и зарубежных ученых по вопросам сельского развития. Исследования прове-

Таблица 1. Показатели развития сельского хозяйства $[9,10]$

Table 1. Agricultural development indicators $[9,10]$

\begin{tabular}{|c|c|c|c|c|c|c|c|c|}
\hline & 2014 & 2015 & 2016 & 2017 & 2018 & 2019 & 2020 & 2020 в \% к 2014 \\
\hline \multicolumn{9}{|l|}{ Производство: } \\
\hline - зерна, тыс. тонн & 105212 & 104729 & 120677 & 135539 & 113255 & 121200 & 133465 & 126,9 \\
\hline $\begin{array}{l}\text { - скота и птицы на убой, тыс. } \\
\text { тонн }\end{array}$ & 9026,0 & 9518,5 & 9853,3 & 10319,0 & 10629,4 & 10866,3 & 11235,6 & 124,5 \\
\hline - крупного рогатого скота & 1621,4 & 1617,1 & 1588,8 & 1569,3 & 1608,1 & 1625,2 & 1630,7 & 100,6 \\
\hline - птицы, тыс. тонн & 4164,3 & 4540,9 & 4622,4 & 4941,0 & 4980,0 & 5014,3 & 5031,0 & 120,8 \\
\hline - свиней, тыс. тонн & 2963,6 & 3083,2 & 3355,1 & 3515,7 & 3744,2 & 3936,8 & 4286,7 & 144,6 \\
\hline $\begin{array}{l}\text { Доля сельского хозяйства в ВВП } \\
\text { РФ, \% }\end{array}$ & 3,9 & 4,3 & 4,27 & 3,9 & 3,8 & 3,9 & 4,1 & $x$ \\
\hline \multicolumn{9}{|l|}{ Доля импорта в потреблении: } \\
\hline - мяса и мясопродуктов, \% & 17,9 & 12,7 & 11,5 & 9,8 & 7,9 & 6,9 & 5,8 & $x$ \\
\hline - молока и молокопродуктов, \% & 23,9 & 21,3 & 20,5 & 19,1 & 17,8 & 18,0 & 18,3 & $x$ \\
\hline
\end{tabular}


дены на основе системного, диалектического, абстрактно-логического, организационного подходов. Объектом исследования являются сельские территории, предметом теоретические и методические вопросы, связанные с разработкой комплекса мероприятий по их развитию.

\section{Результаты и обсуждение}

Разработка проектов по развитию сельских территорий охватывает широкий круг вопросов, без учета которых невозможно подготовить и инициировать комплекс мероприятий, способный обеспечить их сбалансированное позитивное развитие. В общем виде модель формирования программных мероприятий комплексного развития сельских территорий представлена на рисунке 1.

Она отражает следующие этапы методического характера:

- анализ состояния сельской территории;

- прогнозирование направлений и динамики ее развития;

- определение объективных потребностей и выбор наиболее целесообразных изменений свойств сельской территории;

- разработка комплекса мероприятий и обоснование механизмов их реализации.

Рассмотрим содержательную составляющую каждого из выделенных этапов.

В процессе анализа состояния сельской территории исследуется ее ресурсный потенциал, совокупность связей и отношений. В первую очередь изучается наличие и использование трудовых, земельных, промысловых, местных минерально-сырьевых ресурсов, на основе которых реализуются производственные функции сельских территорий. Затем оценивается уровень и возможности развития иных сфер деятельности (аграрного туризма, оздоровительных объектов и проч.). Выявляются направления, степень регулярности и интенсивность трудовых и нетрудовых перемещений жителей территории за ее пределы, возможности удовлетворения их нужд на прилегающих территориях, в ближайших городах, районных центрах. Сельская территория рассматривается не изолированно, а в единой системе расселения «город - село». Оценка внутренних условий и факторов развития сельской местности осуществляется с помощью SWOT-анализа, в ходе которого устанавливаются сильные и слабые стороны, возможности и угрозы. Влияние внешних политических, экономических, социокультурных и технологических факторов выявляется в процессе PEST-анализа.

На этапе прогнозирования направлений и динамики развития сельской территории целесообразно комплексное использование нормативно-ресурсного метода и метода экстраполяции трендов временных рядов. При этом следует учитывать все разнообразие связей между свойствами и объектами сельских территорий, избегая механической пролонгации на прогнозируемый период уже сложившихся тенденций и закономерностей. Применение метода экстраполяции оправдано при относительной устойчивости основных характеристик развития территории (объемов производства, численности населения, уровня развития коммуникаций, интенсивности взаимодействия с городами и районными центрами).

Нормативно-ресурсный метод ориентирован на достижение целевых показателей, или нормативов, обеспеченности сельских жителей социально-культурными объектами, доступности получения услуг с учетом их планируемого ресурсного обеспечения, доходов.

Прогнозы развития сельской территории формируются путем взаимного корректирующего влияния указанных методов, что позволяет использовать преимущества расчетов в обоих направлениях: в одних преимущественно «от прошлого к будущему», в других — «от будущего к прошлому», получая наиболее обоснованные варианты прогнозов.

Определение объективных потребностей и выбор наиболее целесообразных изменений свойств сельской территории осуществляется на основе анализа следующих аспектов:

- развития отраслей экономики как постоянного места работы жителей, обеспечивающего занятость, доходы населения, формирование местных бюджетов (при этом необходимо четкое видение потребностей развития территории с охватом всех сфер экономики, а не только отраслей АПК);

- изучения жилищно-коммунальной инфраструктуры, обеспеченности населения доступным и комфорт- 
ным жильем, наличия распределительных газовых сетей, локальных водопроводов, внутрипоселковых централизованных сетей теплоснабжения, горячего водоснабжения и водоотведения, сооружений по очистке питьевой воды, других объектов благоустройства;

- обеспечения доступности детских дошкольных учреждений, общеобразовательных школ, колледжей и других учебных заведений, дающих общеобразовательную и профессиональную подготовку, учебных заведений музыкального и художественного профиля;

- наличия и доступности фельдшерско-акушерских пунктов, медицинских и здравпунктов, больниц, амбулаторно-поликлинических учреждений, аптек, оздоровительных детских лагерей и других объектов лечебно-профилактического назначения;

- степени удовлетворения культурных и духовно-нравственных потребностей населения сельских территорий (наличия и содержательной наполненности клубов, Домов культуры, кинотеатров, музеев и проч.);

- наличия условий для занятий физкультурой и спортом (спортивных площадок, залов, школ, плавательных бассейнов, физкультурно-оздоровительных комплексов);

- обеспечения доступности социального обслуживания (служб занятости, органов пенсионного обеспечения и социальной защиты населения, домов-интернатов для инвалидов и престарелых и др.);

- наличия предприятий торговли и общественного питания (стационарных магазинов, мобильных средств торговли, рынков, столовых, кафе, ресторанов);

- доступности организаций бытового обслуживания (стационарных и передвижных приемных пунктов, мастерских, ателье, парикмахерских, прачечных, химчистоки др.)

- развития информационных и телекоммуникационных сетей (наличие отделений связи, АТС, телефонных сетей, интернета);

- развития дорожно-транспортных коммуникаций, соединяющих районные и административные центры сельских поселений с небольшими селами и хуторами, внутрипоселковых дорог, обеспечивающих связь с производственными объектами К(Ф)Х, наличия пассажирского автобусного сообщения;

- сохранения и восстановления экологии сельской местности (рекультивация земельных участков, улавливание и обезвреживание выбросов на объектах транспортной, коммунальной, социальной инфраструктур, соблюдение режима санитарно-защитных зон объектов хозяйственной и иной деятельности, оказывающих вредное воздействие на атмосферный воздух, осуществление мер по обеспечению безопасного обращения с отходами производства и потребления, обезвреживание и безопасное захоронение непригодных и запрещенных к применению пестицидов и химикатов организация накопления, сбора, транспортирования, обработки, утилизации, обезвреживания и захоронения твердых коммунальных отходов и др.);

- обеспечения доступности госуслуг, безопасности жизнедеятельности и правопорядка.

Проведенный анализ создает основу для выбора наиболее целесообразных изменений свойств сельской территории на основе имеющихся ресурсов, установленных пропорций и возможностей получения господдержки. На этом этапе необходимо обеспечить многоуровневый подход, позволяющий выделить проблемы сельского поселения, отдельных социальных групп и сельских жителей. Местными органами власти должна быть организована продуманная система выявления наиболее насущных проблем местного сообщества, их ранжирования, гармонизации и отбора наиболее значимых, решение которых повлечет получение мультипликативного эффекта.

Формирование комплекса мероприятий по развитию сельских территорий осуществляется на основе следующих методических положений:

- целевая ориентированность на обеспечение физического наличия стационарных или мобильных объектов обслуживания, их доступность, качество и удовлетворенность населения услугами;

- создание единых территориальных систем обслуживания населения с головными центрами в крупных сельских поселениях, районных центрах, городах и периферийными объектами, приближенными к жителям мелких поселений;

- развитие как вертикальных (от небольшого сельского поселения до крупного районного центра), так и горизонтальных связей, предусматривающих размещение тех или иных базовых предприятий и учреждений обслуживания в разных населенных пунктах одного порядка с учетом потребностей прилегающих (соседних) территорий.

В зависимости от конкретных условий (характера сельского расселения, удаленности поселения от крупного города, развития дорожно-транспортных коммуникаций, демографической ситуации, направления миграции, инвестиционной активности и др.) целесообразны различные схемы построения территориальных систем обслуживания, предусматривающие большую или меньшую степень централизации. Однако распространенная практика, когда все виды услуг и объекты культуры сосредоточены в районном цент ре, а сельские жители не имеют иной возможности для получения этих услуг, кроме поездки в райцентр, должна дополняться созданием многофункциональных пунктов по обслуживанию сельского населения в крупных межселенных центрах, центрах сельских муниципальных образований, что позволит значительно приблизить услуги к месту жительства основной массы сельского населения;

- в целях экономии бюджетных средств необходимо предусмотреть расширение функционального назначения зданий, использование модульных архитектурно-планировочных решений, создание многопрофильных центров общественного обслуживания;

- необходимо обеспечить этапность реализации мероприятий в краткосрочном, среднесрочном, долгосрочном периоде.

При прочих равных условиях первостепенное развитие экономики, строительство дорог, приобретение транспорта, информационные и телекоммуникационные сети обеспечат наибольший социально-экономический эффект. Развитие сельской экономики даст импульс развитию сельских территорий, обеспечит занятость и доходы жителей, а значит и налоговые поступления муниципалитетов, расширит их возможности саморазвития и использования форм государственной поддержки на основе софинансирования. Строительство дорог, улучшение дорожного покрытия, а также развитие информационных и телекоммуникационных сетей позволит повысить привлекательность сельской местности для постоянного проживания, расширит сферы приложения труда не только в крупных селах, но и за их пределами даст возможность использовать тренд на экологически чистое питание и сельский образ 
жизни для миграционного прироста и повышения качества жизни сельского населения.

На этапе обоснования механизмов реализации мероприятий по развитию сельских территорий необходимо ориентироваться не только на средства муниципалитетов и сельского населения, но и активно использовать меры государственной поддержки. При этом следует учитывать, что они предусмотрены не только в рамках ГП КРСТ, но и в других государственных программах и национальных проектах, а именно: ГП «Развитие здравоохранения», ГП «Развитие образования», ГП «Социальная поддержка граждан», ГП «Доступная среда», ГП «Обеспечение доступным и комфортным жильем и коммунальными услугами граждан Российской Федерации», ГП «Содействие занятости населения», ГП «Развитие культуры», ГП «Охрана окружающей среды», ГП «Развитие физической культуры и спорта», ГП «Информационное общество», ГП «Развитие транспортной системы», НП «Здравоохранение»; НП «Образование»; НП «Демография»; НП «Культура»; НП «Безопасные и качественные автомобильные дороги»; НП «Экология»; НП «Малое и среднее предпринимательство и поддержка индивиду-

\section{СПИСОК ЛИТЕРАТУРЫ}

1. Постановление Правительства РФ от 31.05.2019 N 696 (ред. от 31.12.2020) «Об утверждении государственной программы Российской Федерации «Комплексное развитие сельских территорий» и о внесении изменений в некоторые акты Правительства Российской Федерации» - Режим доступа: http://www.consultant.ru/document/cons_doc_LAW_326085/

2. Приказ Минэкономразвития России от 23.03.2017 N 132 (ред. от 07.09.2018) «Об утверждении Методических рекомендаций по разработке и корректировке стратегии социально-экономического развития субъекта Российской Федерации и плана мероприятий по ее реализации» http://www.consultant. ru/document/cons_doc_LAW_214725/

3. Приказ Минсельхоза России от 10.06.2020 N 313 "Об утверждении Порядка отбора проектов комплексного развития сельских территорий или сельских агломераций" (Зарегистрировано в Минюсте России 10.07.2020 N 58898)

4. Федотова М.Ю., Ломакин А.А. Устойчивое развитие сельских территорий как направление стратегии их функционирования Пенза, издательство: Пензенский государственный аграрный университет. 2013. С. 200 альной предпринимательской инициативы»; НП «Цифровая экономика Российской Федерации». Определенный ресурс представляет собой и частный бизнес, пока мало задействованный в развитии сельских территорий, но располагающий необходимыми финансово-экономическими, административными возможностями и заинтересованный в стабильности и позитивном развитии территории локализации своего бизнеса. Перспективными направлениями социально ориентированной деятельности частного бизнеса в сельской местности являются: поддержка системы образования и подготовки кадров, оздоровление и спорт, улучшение коммуникационной доступности территории.

Успех разработки и реализации программных мероприятий и решение проблем развития сельских территорий в значительной мере будут зависеть от объединения усилий и согласованных действий органов местного самоуправления и органов государственной власти региона, заинтересованности частного бизнеса, взаимодействия с операторами разных государственных программ и проектов, предусматривающих меры государственной поддержки.

5. Костяев А. И. К вопросу о научных основах разработки стратегий развития сельских территорий. Аграрная наука Евро-Северо-Востока. 2020;21(4):462-474. DOI: https://doi. org/10.30766/2072-9081.2020.21.4.462-474

6. Бондаренко Л.В. Российское село в эпоху перемен: занятость, доходы, инфраструктура / Москва, Издательство: ФГУП «ВО Минсельхоза России». 2003. 510 с.

7. Комплексное развитие сельских территорий: факторы, институты и механизмы опережающего развития / Б.А. Ковтун, В.Н. Папело, В.В. Ярманов; Новосиб. гос. аграр. ун-т. - Новосибирск: ИЦ НГАУ «Золотой колос», 2019. - 400 с

8. Шевченко В., Белоусов В., Белоусов А. Организация планирования социального развития сельских территорий. АПК: экономика, управление. 2004;(4): с. 56-66.

9. Бюллетени о состоянии сельского хозяйства (электронные версии). Балансы продовольственных ресурсов. - Режим доступа: https://rosstat.gov.ru/compendium/document/13277 (дата обращения: 12.04.2021).

10. Национальные счета. Валовой внутренний продукт. Режим доступа: https://rosstat.gov.ru/accounts (дата обращения: 12.04.2021).

\section{НОВОСТИ•НОВОСТИ•НОВОСТИ॰НОВОСТИ॰}

\section{На развитие сельских территорий Ставрополья в текущем году направлено более 540 млн рублей}

В рамках заседания правительства Ставропольского края были подведены промежуточные итоги реализации в регионе государственной программы «Комплексное развитие сельских территорий» в текущем году. На осуществление мероприятий направлено около 541 млн руб., сообщили в пресс-службе губернатора. Среди реализованных мероприятий - шесть проектов благоустройства в сельских территориях, построенные или реконструированные объекты водоснабжения общей протяженностью 2,5 км.

Отдельное внимание на заседании уделили ведомственному проекту «Современный облик сельских тер- риторий». В его рамках в 2021 году реализуются 23 объекта в 6 округах края.

Бюджет программы комплексного развития сельских территорий на 2022 г. запланирован в объеме более 750 млн рублей.

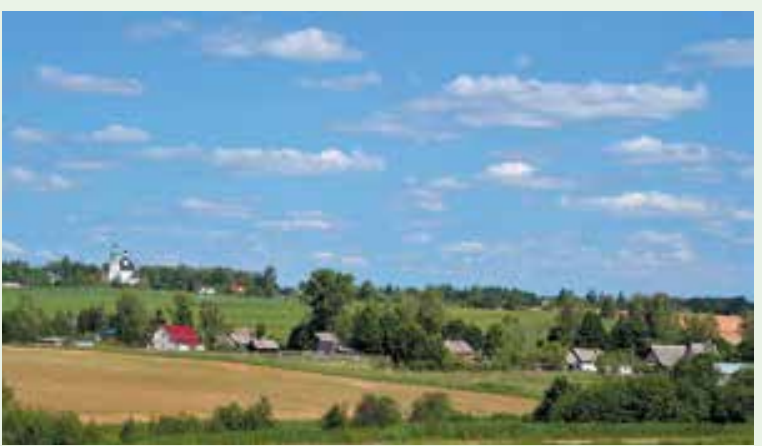

